\title{
INFLUENCE OF TEXTURE ON DRAINABILITY, SPLASH AND SPRAY IN FLEXIBLE PAVEMENTS
}

\author{
JOSE MANUEL SANZ GARCIA ${ }^{1^{*}}$, \\ MANUEL ROMANA GARCIA ${ }^{2}$, \\ JOSE ANTONIO RAMOS GARCIA ${ }^{3}$ \\ ${ }^{1}$ Road Projects Department, Ineco, Madrid, Spain \\ ${ }^{2}$ Transportation Department, Technical University of Madrid, Madrid, Spain \\ ${ }^{3}$ Rauros ZM, Tres Cantos, Madrid, Spain
}

Received 21 December 2020; accepted 19 February 2021

\begin{abstract}
Although the splash and spray phenomenon produced by heavy trucks on road pavements is not a significant issue in relation to traffic safety, it may cause considerable inconveniences for those driving cars or motorbikes. This paper addresses the issue of pavement engineering with regard to surface characteristics; particularly pavement texture and its influence on water mobilization and projection in conditions of wet weather and heavy traffic. Considering the theoretical concept of pavement macrotexture, the analysis starts with the hypothesis concerning a relationship between Mean Profile Depth (MPD) and water splashed during rain. In order to focus on the impact of texture on splash and spray, a field experiment was carried out to test the hypothesis using 5 test tracks on a range of different pavement textures. The experiment was performed using a Traffic Speed Drain Meter (TSDM), which is a new drainability survey device presented to PIARC for approval. This equipment employs the laser and image technology and allows one to simultaneously obtain MPD and water splash data. The results of drainability and MPD were compared for each test track. Having analysed the pavements with different MPD ranges in the experiment, it has been concluded that MPD and water splashed apparently
\end{abstract}

\footnotetext{
*Corresponding author. E-mail: jmsanz@ciccp.es 
have an inversely proportional relationship. In addition, the TSDM proved to be a suitable equipment (repeatability) at an affordable cost (high performance of data collection). Finally, it has been concluded that there is a way to reduce splash and spray adjusting the infrastructure rather trying to solve the issue modifying vehicle moving modes. Therefore, if the issue is properly addressed by civil engineers and road managers, road safety in the areas of heavy rain may be improved at an affordable cost. The experiment presented here is considered a starting point opening the path for further research.

Keywords: drainability, mean profile depth (MPD), pavement, road, splash and spray, texture.

\section{Introduction}

Splash and spray from heavy vehicles occur on wet pavements and causes inconveniences for those driving cars or motorcycles. The phenomenon analysed scientifically since the 1950s has been known for quite a time. The systems of different configurations and designs aimed at eliminating the phenomenon and protecting the drivers have been developed since the 1880s (Tennent, 1886; Marion, 1915). It was first perceived as a hazardous phenomenon for traffic safety, therefore, a great deal of research was carried out by different organizations, especially the Road Research Laboratory of the United Kingdom (Maycock, 1966) and the Federal Highway Administration of the United States (Weir et al., 1971). The studies regarding splash and spray were initially focused on the loss of visibility and reduction of contrast (Campbell, 1984), considering that drivers with low contrast sensibility due to deficiencies in their eyesight may be more likely to suffer a crash under reduced conditions of visibility (Koppa et al., 1992). Motorcyclists were also identified as a high-risk group (Tromp, 1985). However, the National Highway Traffic Safety Administration of the United States developed a study for the Congress in 1994 and excluded splash and spray from the list of significantly hazardous phenomena for traffic safety, based on several studies of accident rates carried out in the previous decades (National Highway Traffic Safety Administration, 1994).

Notwithstanding the above said, splash and spray from heavy vehicles continues posing inconveniences for drivers and particularly motorcyclists. Consequently, since the 1990s several studies have been carried out (Eklund, 1991; Koppa et al., 1992; Pilkington, 1990; Sheppard, 1989) with regard to what can be done to reduce splash and spray in the areas of protective devices (fenders and mudguards), as well as in the area of car tires and tire slippage. Pavement surface improvements are recognized internationally as being of primary importance in reducing splash and spray (Ashton \& Baas, 1998). 
Road-based options include texture improvements to chip seals and porous asphalt surfaces and to eliminate standing water through improved road geometry and drainage.

This paper takes an infrastructure-related approach and presents research regarding the influence of pavement texture on the water splash phenomenon occurring on wet roads. A joint research project in this field implemented by the company Euroconsult and the Technical University of Catalonia (Spain) and published by the Transportation Research Board (Pérez-Jiménez et al., 2011) was the foundation for the development of a new survey device measuring drainability and texture through Mean Profile Depth, MPD (Benatov et al., 2013). Five Test Tracks were surveyed using this device in order to analyse the influence of surface texture on water splash.

\section{Literature review}

The characteristics of the splash and spray phenomenon were defined in the second half of the 20th century. Splash and spray is a combined concept which may be considered as two different water mobilizations (Pilkington, 1990):

Splash is "the mechanical action of a vehicle's tire forcing water out of its path. Splash is generally defined as water drops greater than $1.0 \mathrm{~mm}$ (0.04 inches) in diameter, which follow a ballistic path away from the tire."

Spray is "when water droplets, generally less than $0.5 \mathrm{~mm}$ (0.02 inches) in diameter and suspended in the air, are formed after water has impacted a smooth surface and been atomized."

In 1978, (Weir et al., 1978) explained splash and spray through different water mobilization mechanisms including capillary adhesion, tread pickup, bow splash waves and side splash waves, as shown in Fig. 1.

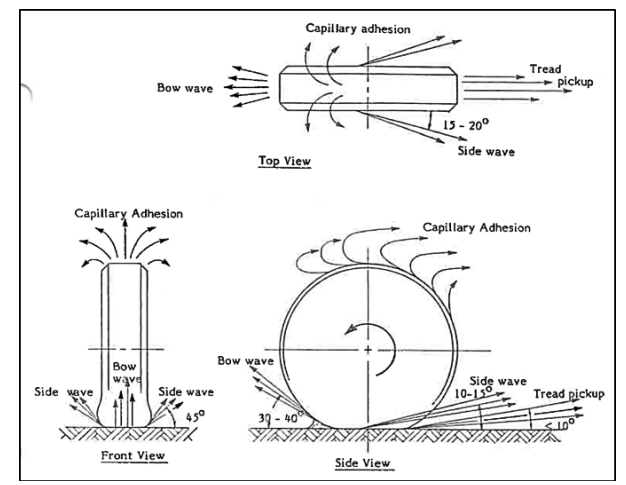

Figure 1. Mechanisms of splash and spray (Weir et al., 1978) 
The main factors affecting the generation of splash and spray are also known (Resendez et al., 2007) and listed below:

- water film thickness present on the road surface (function of pavement porosity, geometry, drainage capability, texture, and rainfall intensity);

- vehicle speed;

- tire geometry and inflation and tread design and condition;

- vehicle aerodynamics;

- vehicle spray suppression devices;

- wind vector.

Since the 1990s, several inventions have been developed to measure pavement drainability and wetting (Anderson et al., 1998; Benatov et al., 2013; Brochard \& Khoudeir, 2010; Escriba \& Jiménez, 2015; Takashi et al., 1994).

Although the National Highway Traffic Safety Administration (NHTSA) issued a study to the Congress of the United States concluding that splash and spray is not a significant road safety problem (National Highway Traffic Safety Administration, 1994), its impact on user road experience is still under research today.

Retroreflectivity measurements were performed to investigate wet conditions and the influence of splash and spray on road markings (Pike et al., 2007). Not only road markings, but also the relationship between the loss of visibility and pavement type under splash and spray conditions was studied in 2010. However, it should be note that the pavement surface factor in the models used by the aforementioned study was entered as one or zero numbers depending on the pavement type (porous asphalt $=1$, other asphalt $=0$ ), and the authors did not consider pavement texture as a factor (Rungruangvirojn \& Kanitpong, 2010a).

In 2012, a survey was carried out to assess the impact of splash and spray on road users. As suggested by the research, participants experienced a greater degree of inconvenience (i.e., higher rates of obstructed concentration, distraction and risk and lower rates of confidence and control) for manoeuvres related to following other vehicles versus manoeuvres related to passing (particularly when following a dump truck) under splash and spray conditions (Flintsch et al., 2012). The influence of pavement macrotexture (characterized through MPD) on drainability (or water evacuation ability) has been recently investigated through field tests and finite-element models (Srirangam et al., 2014).

Considering the results of the field tests and the finite-element models, Srirangam et al. (2014) considered that the wet friction coefficient increases with MPD at a constant depth of surface water. The 
authors came to conclusion that a larger MPD would increase the wet friction coefficient and thus reduce the risk of wet weather accidents.

In 2014, a model to measure splash and spray was developed by a team headed by G. Flintsch for the Federal Highway Administration (Flintsch et al., 2014). The model comprised three elements: a water film thickness model, an exposure model to estimate the amount of water to be projected by the tire, and a splash and spray model which predicts the likelihood of splash and spray occurrence based on the other two models.

The infrastructure component in this research was represented by the water film thickness model, which predicted water film thickness on pavement surfaces based on pavement surface properties and rain intensity. The team considered four infrastructure factors affecting splash and spray: pavement geometry (introduced by considering longitudinal gradient and pavement cross slope), pavement texture (involving Manning's roughness coefficient), pavement porosity (distinguishing between dense asphalt mixes and porous asphalt) and pavement drainage (particularly considering the influence of longitudinal drains installed on the road).

The water film thickness model predicts water film thickness on pavement surfaces based on pavement surface properties and rain intensity and is based on laboratory experiments. The model used (Anderson et al., 1998) was based on the kinematic wave equation and included Manning's roughness coefficient as a variable.

$$
W F T=\left(\frac{n L i}{36.1 S^{0.5}}\right)^{0.6}-M T D,
$$

where WFT - water film thickness, in; $n$ - Manning's roughness coefficient; $L$-drainage path length, in; $i$ - rainfall rate, in/h; $S$ - slope of drainage path, in/in; MTD - mean texture depth, in.

In 2011, the University of Southern California (USC) carried out an experiment about the spray development behind a tire rolling over wet pavement. Several tires with different kinds of grooves were tested and the process was monitored by a laser and a video camera (Plocher, 2011). The aim of the project was to determine a technique for evaluating the time-to-drain. This concept represents the time interval required to remove all (or most) of the liquid in a tire groove. Although the study was interesting considering the reaction of the vehicle, the influence of infrastructure (pavement) was not considered in this study.

One of the latest significant studies on the relationship between pavement drainability and macrotexture was performed recently in Virginia using several surveys (Mogrovejo et al., 2016). The study covered 32 different road sections, involving almost all types of asphalt pavement used in the state of Virginia. The team ran several surveys 
with four different types of equipment: CT meter for static macrotexture measurements, HSLD for dynamic macrotexture measurements, GripTester for slip friction measurements and OBSI for tire-pavement noise measurements.

The aim of the study was to characterize the macrotexture in detail, which allowed researchers to propose an index for providing a good correlation with asphalt surface properties by estimating the effective area for water evacuation (EAWE). The proposed EAWE index (measured in $\mathrm{mm}^{2}$ ) defines the area between the tire enveloping profile and the pavement profile where tire-pavement contact occurs. EAWE index is defined as following:

$$
\operatorname{EAWE}_{i}=\left(\frac{b_{i}+b_{i+1}}{2} h\right),
$$

where $b_{i}$ is the difference of the $i$-th data point in the enveloping profile minus the $i$-th data point in the original pavement profile, $h=0.5 \mathrm{~mm}$, which is the spacing between data points in the profiles.

That research showed that texture measured as the mean profile depth (MPD) overestimates the pavement ability to evacuate water (Mogrovejo et al., 2016), and it was concluded that such drainability indicator as EAWE gives a more realistic relationship with real pavement texture, it also better correlates with pavement characteristics than MPD.

Recently, the problem of visibility loss due to splash and spray has been analysed with mathematical scattering formulation (Yu \& Sun, 2018), considering the principle of multiple scattering of photons.

LRM, \%

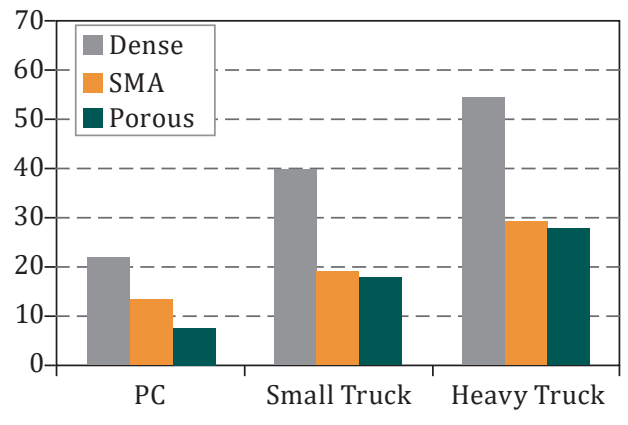

CCM, \%

b)

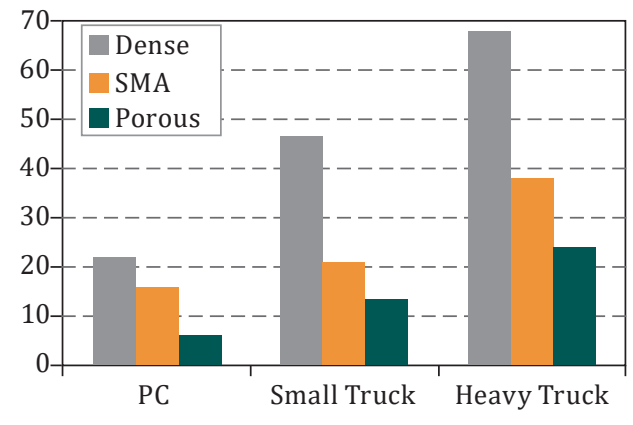

Figure 2. Effect of visibility loss (percentage of light reduction (LRM) and percentage of colour change (CCM)) for each mix type. PC, passenger car (Rungruangvirojn \& Kanitpong, 2010b) 
Just as in Plocher's study, the influence of infrastructure has not been considered in this case.

A study focused on the visibility loss that considers an infrastructure approach (Rungruangvirojn \& Kanitpong, 2010b) analyses it by using laser technology and digital LUX meters. In this study, two test procedures were used for measuring visibility loss due to splash and spray. The first procedure is called the light reduction method (LRM) and the second is called the colour changing method (CCM). The tests were carried out over porous asphalt (PA), stone mastic asphalt (SMA) and conventional dense asphalt. The main findings about the influence of infrastructure are displayed in Fig. 2.

The results are logical, considering that porous asphalt has a high void content (about 20\%) unlike SMA (4-7\% in SMA) and conventional dense asphalt (typically 3-6\%).

\section{Experimental study}

\subsection{Description of survey equipment}

In order to analyse the correlation between pavement texture characterized through MPD and water evacuation, the authors used a new device called 'Traffic Speed Drain Meter' (hereafter TSDM, known in Spanish as DVT). Leonardo Benatov (private engineering company), Felix Perez and Rodrigo Miro (Polytechnic University of Catalonia) patented this equipment in 2013.

The TSDM measurement system is based on recording the amount of water splashed by a tire driving over a wet pavement. This system consists of a towed water tank which releases a constant stream of water ahead of a given standard tire. A high-resolution camera captures the water drops as they cross a measurement plane illuminated by a laser light source on its back. The measurement plane is close to the tire pavement interface and the drops are measured at different heights. Based on this system, a range of measurement parameters and variables has been defined and set, such as the position of the measurement plane, the type of tire, the water flow to provide, and the way the water falls on the pavement, together with the type of camera and its measurement conditions.

As shown at the beginning of the measurement, it is necessary to release a constant and controlled stream of water over the pavement ahead of the test tire in order to measure splash and spray. To do so, the system is installed under a standard trailer with a water tank on top of it, which can be towed by a commercial truck. The following figure 
shows the commercial trailer towed by a SCRIM® measurement system, but it can be towed by any type of vehicle with enough power to keep a steady, fixed speed. An installation sample is shown in Fig. 3.

The performance of the device is based on the controlled simulation of the conditions, under which the water splash and spray takes place, in order to collect this information and process it by means of image analysis. To such end, a certain volume of water is released in front of the measurement tire, thus creating a controlled water film over the pavement. The wheel used to generate the splashes over the wet surface is mounted on tires with the tread pattern commonly used in the automotive industry, and is ballasted with a constant load so as to keep permanent contact with the driving surface. The lighting system and the camera must be protected from the surrounding light, so the whole ensemble is covered by a case or box protecting and keeping the tire, the
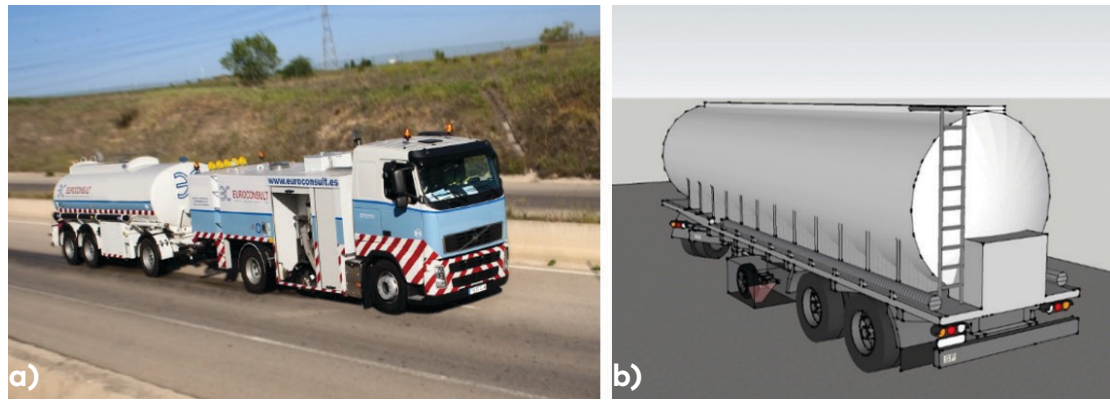

Figure 3. a) view of the Traffic Speed Drain Meter (TSDM) in the process of conducting a survey; b) view of the trailer with a tank capacity of $15000 \mathrm{~L}$ and the system of water projection before the tandem axle

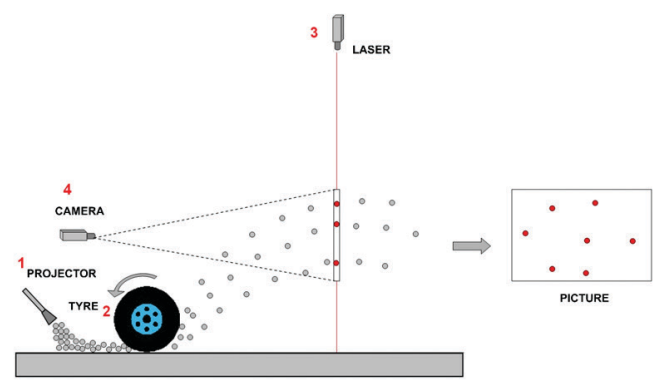

a)

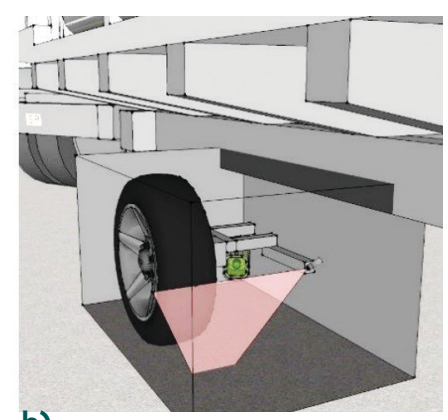

b)

Figure 4. a) measurement principle of the Traffic Speed Drain Meter and the diagram of the measurement tire under the vehicle; b) water projection system installed on the trailer and plane for image collection 
measurement plane and the high-speed camera in the dark. The diagram in Fig. 4 shows the basic measurement system of the device.

The measurement plane is perpendicular to the road surface. The truck used a conventional tire, with an aim to simulate a typical heavy vehicle. The water is controlled by the equipment, which provides a constant water flow to the tire to produce splash and spray. The water flow is similar to that used in the SCRIM survey (Standard UNE 41201:2020). The camera used in the survey was a high-resolution colour camera and the laser worked at $650 \mathrm{~nm}$ wavelength.

This equipment provides repeatable and reliable measurements. The device was presented to PIARC for assessment and approval (Moffatt, 2016), as well as presented to the European Pavement and Asset Management Conference in Mälmo, Sweden (Sánchez Domínguez et al., 2012). In addition, the TDSM has been considered as a 'probe vehicle' at the PIARC International Seminar "Global Approaches on Sustainable Pavements", held in Cancun, Mexico (Briessinck \& Moffatt, 2017).

\subsection{Comparison with the existing technology}

The existing technology used to measure splash and spray has evolved significantly since the first prototypes. Several different approaches have been tried since the 1960s. They can be classified by the type of measurement system they use.

Physical collection: used in early studies, were based on physical collection of splashed water droplets. Several authors used this method (Maycock, 1966; Pilkington, 1990; Ritter, 1974). The problem with this method consists in the fact that results cannot be repeated and it is difficult to reproduce the physical collection.

Static optical methods: the splash and spray phenomenon is assessed with the help of static laser technology. Some lasers are installed on the fixed structures and cameras are placed at each side of the test track. Various studies have been performed using this measurement system (Chatfield et al., 1979; Koppa et al., 1985; Society of Automobile Engineers, 2011). The main problems with this system are the changes in contrast, the subjectivity of the observation and the occlusion occurring at moderate speeds.

Dynamic vehicle-mounted systems: this technology consists of lasers which are mounted on the survey vehicle. The lasers may assess the water in different ways (directly toward the pavement, toward a plane perpendicular to the pavement). This system may be aided by high-definition cameras. This method has materialized via several different prototypes over in the last few years (Benatov et al., 2013; Tang \& Flintsch, 2015). 
The "Traffic Speed Drain Meter", equipment used in this experiment, was designed by Benatov et al. and its main advantages is the repeatability of the measurements, the ease of data collection (high performance) and its affordable cost (dynamic vehicle).

\subsection{Survey features}

Once in the field, the survey was performed, setting the following parameters:

- vehicle speed: $25 \mathrm{~km} / \mathrm{h}$;

- image time acquisition ratio: 10 images/s;

- image spatial acquisition ratio: 1.44 images/m.

No data were collected in the roundabouts, the water supply was cut off as a safety measure to prevent accidents.

\subsection{Test tracks surveyed}

In order to have enough data and assess different roads with different pavement structures and surfaces, five test tracks in three roads in the Madrid region were surveyed with the TSDM device. These roads have three well differentiated pavements: two of them were dense-graded bituminous mixtures, and the other one had an open-graded mixture.

A map with the track route is displayed in Fig. 5.

The test tracks surveyed are those set out below:

- Roundabout "Río de Janeiro" (starting),

- Test Track 1: Road Río de Janeiro roundabout - El Nogal. Starting station: $0+140$. Final station: $1+970$,

- Test Track 2: Road Algete - Exit to Fuente el Saz de Jarama. Starting station: $3+310$. Final station: $3+810$,

- Test Track 3: Road Exit from Algete - Fuente el Saz de Jarama. Starting station: $3+890$. Final station: 8+290,

- Test Track 4: Road Fuente el Saz de Jarama - Exit to Valdetorres. Starting station: $8+390$. Final station: $9+450$,

- Test Track 5: Road Junction at Río de Janeiro roundabout. Starting station: $19+550$. Final station: $20+930$.

The test tracks have different texture ranges. Test Track 1 had MPD values between 0.2-0.8, while Test Track 2 and 4 were between 0.5-0.8. Test Track 3 was between $0.3-1.0$ and Test Track 5 had an MPD range between 0.4-1.0. Different texture ranges allude to dissimilar aggregate grading: dense-graded, more open-graded, with more quantity of fine aggregates, or a higher degree of coarse aggregates. It was found useful to analyse the trends between texture depth and water splashed for different configurations. These textures are presented in Fig. 6. 
Jose Manuel Sanz

Garcia,

Manuel Romana

Garcia,

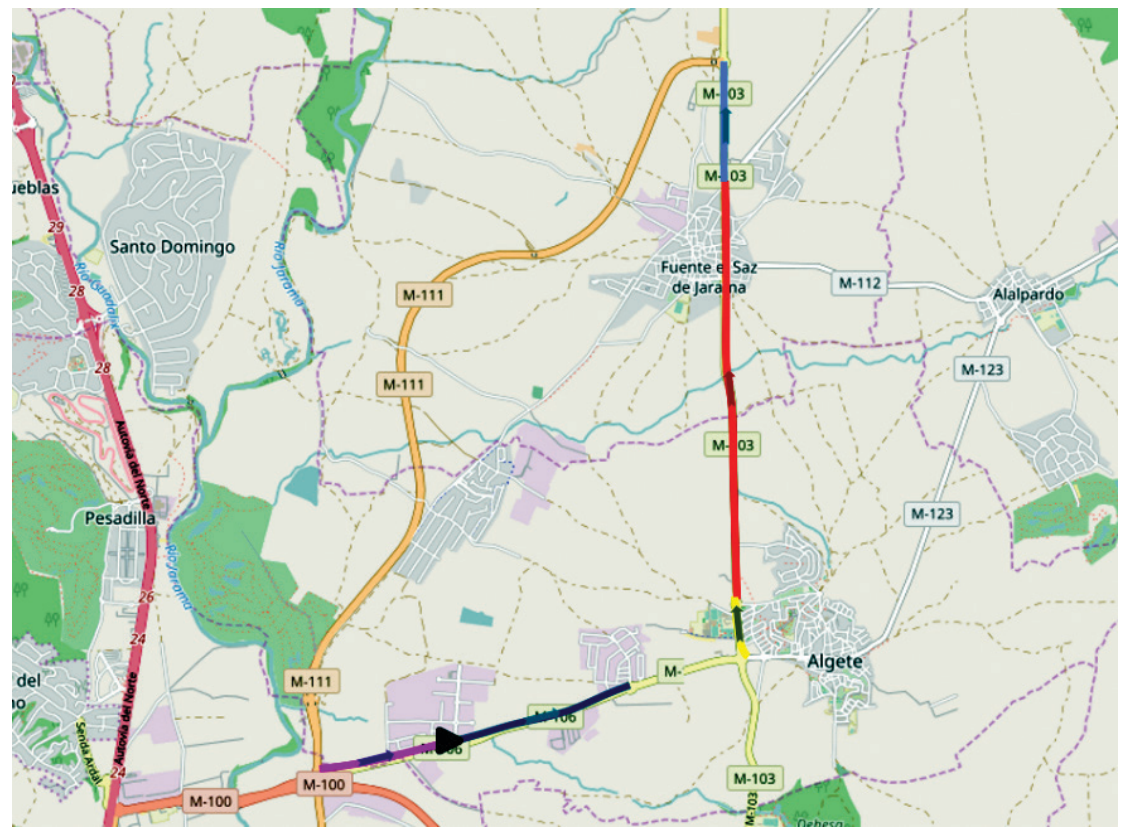

Jose Antonio Ramos Garcia

Influence of Texture on Drainability, Splash and Spray in Flexible

Pavements

Figure 5. Test tracks analysed. Test Track 1 is marked dark blue, Test Track 2 - yellow, Test Track 3 - red, Test Track 4 - light blue, Test Track 5 - purple. Map source: Openstreet Maps
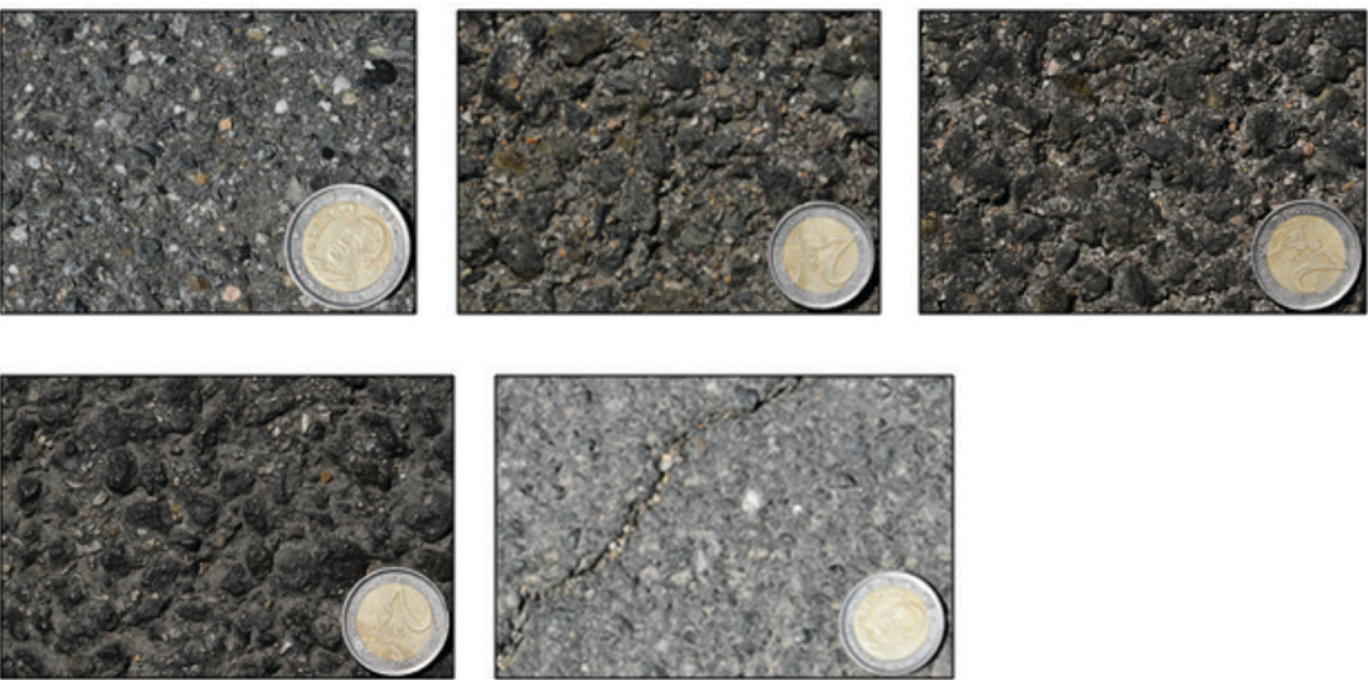

Figure 6. Photographs of the Test Tracks 1 to 5 (from left to right and up to down) 


\section{Theoretical analysis}

The methodology applied to the conducted drainability analysis is based on the software procedures developed for this purpose. The software receives digital images and conducts two different types of analysis: image analysis and contextual analysis.

\subsection{Image analysis}

This task consists in determining the number of water droplets belonging to or present in a picture. To achieve this, the software performs normalization of the illuminated plane, which allows extracting those elements (water droplets) from the picture background. A sample is shown in Fig. 7.

Once we identified the number of water droplets belonging specifically and only to the illuminated plane of each picture, the software proceeds with calculating their representative values; that is to say, the "droplets characterization". The values obtained for each water droplet are as follows:

- coordinates bounding-box (droplet position),

- droplet size (number of pixels),

- droplet mass (droplet size $x$ illumination intensity),

- centre of mass (1st moment),

- covariance matrix (2nd moment).

After having determined, characterized and filtered the digital images, the software starts the process of generating the image

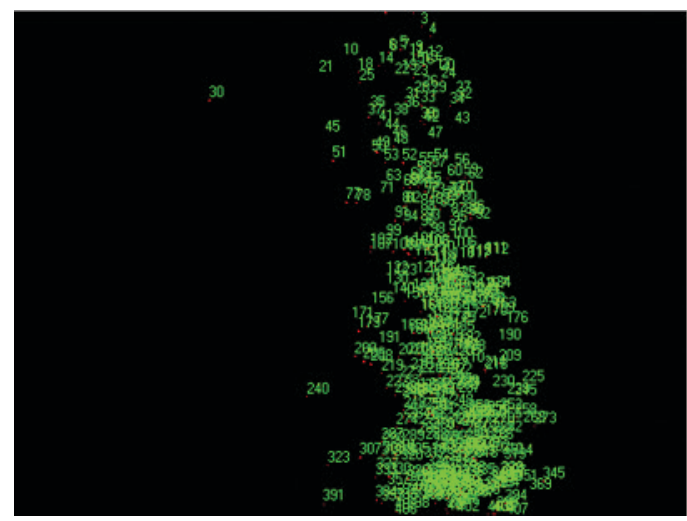

Figure 7. Segmented digital picture from image processing software with identified water droplets 
descriptor, which will characterize each picture. This process involves three tasks:

- image division in sections and calculation of their histograms,

- generation of the descriptor vector,

- classification of the image descriptor.

Once the image descriptor vector has been classified, the assessment of the punctual pavement drainability is made. The equipment, in addition to providing the drainability analysis, also gets an MPD value in the same track point with the help of the laser profilometer. A onetime measurement is not enough to characterize a road stretch, so it is necessary to evaluate its coherence with the adjacent values in order to get a track measurement. For this reason, the software performs the second process called Contextual Analysis.

\subsection{Contextual analysis}

The contextual analysis involves generation of the contextual 2nd order descriptor prior to its classification. In order to generate the 2nd order descriptor, it is necessary to accumulate certain drainability measurements for consecutive pictures. This is performed with a buffer which allows accumulating measurement data for a 10-meter stretch of pavement. This buffer has a circular structure; i.e., once " $n$ " pictures are obtained, incorporating a new picture, the first picture obtained is lost. It is a concept similar to the moving average used in other applications related to road engineering.

After calculating this second descriptor, the software starts the classification process. In this task, similar as it occurred in the classification of the 1 st order descriptor, the obtained value is then entered into a neural network developed exclusively for this descriptor, which is independent from the previous one. This neural network classifies the descriptor by taking the coherence of the contextual information into account. When the software finishes the analysis for all digital images in a road track, the application generates a result chart which shows the road track divided into drainability categories.

\section{Results: the influence of texture on drainability at the test tracks}

In order to present the quantitative information about the collected data, Table 1 lists the main parameters for each test track. Each record 
means one value for MPD, one value for water droplets (number) and one value for water droplets (mass).

Table 1. Quantitative information about the collected data

\begin{tabular}{cccccc}
\cline { 2 - 5 } & Test Track 1 & Test Track 2 & Test Track 3 & Test Track 4 & Test Track 5 \\
\hline Starting station & $0+140$ & $3+310$ & $3+890$ & $8+390$ & $19+550$ \\
Final station & $1+970$ & $3+810$ & $8+290$ & $9+450$ & $20+930$ \\
\hline Length & $1.83 \mathrm{~km}$ & $0.50 \mathrm{~km}$ & $4.40 \mathrm{~km}$ & $1.06 \mathrm{~km}$ & $1.38 \mathrm{~km}$ \\
\hline Number of records & 182 & 51 & 325 & 107 & 139 \\
\hline
\end{tabular}

Given that the research team had a dynamic measurement vehicle, the tests could be performed on the same day, so the effect of wind was not considered in this study. The results in terms of splash produced by the truck are summarized in the following charts, which represent the number of droplets identified during the route, distinguishing between different test tracks, and the mass of the water droplets.

The following charts in Fig. 8 to Fig. 12 show the number of water droplets in the $y$ axis versus pavement texture in the $x$ axis.

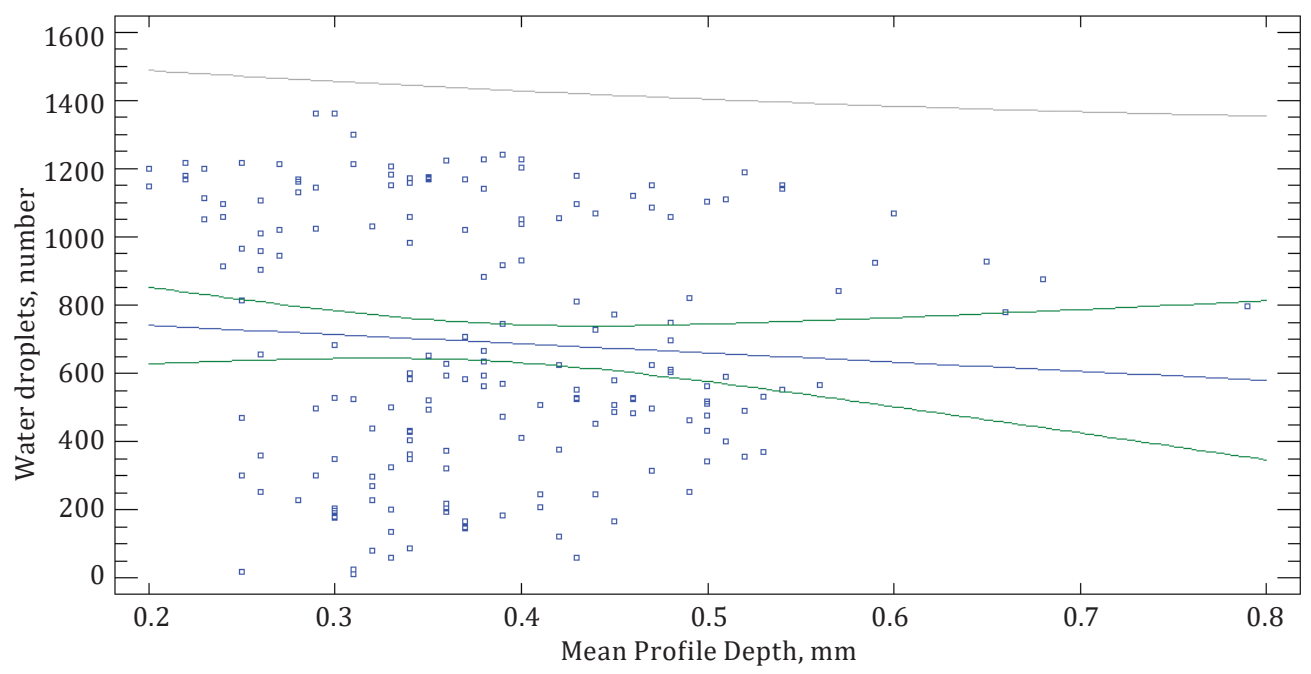

Figure 8. Number of water droplets on Test Track 1 
Note: the lines exhibited by the figures are given by the statistic software and have the following meaning: dark blue line is the best adjustment, green lines are the lower-confidence limits, and light grey lines show external prediction limits.

Confirmation of the hypothesis is certainly weak, considering the regression between drainability and pavement texture. However, a slight trend can be observed for the highest MPD values: in most of cases, when MPD is higher, the amount of evacuated water increases, and the lower the texture value, the lower amount of water is mobilized. The relationship appears relatively clear for Tracks 1, 3 and 5. However, for Tracks 2 and 4 it seems to be relatively horizontal (low variation of water splashed with texture variation). Nevertheless, the inversely proportional relationship seems to be present in most cases.
Jose Antonio Ramos Garcia

Influence of Texture on Drainability, Splash and Spray in Flexible Pavements

Plot of Fitted Model

Water droplets T2 $=872.255-5.01961 \times$ MPD T2

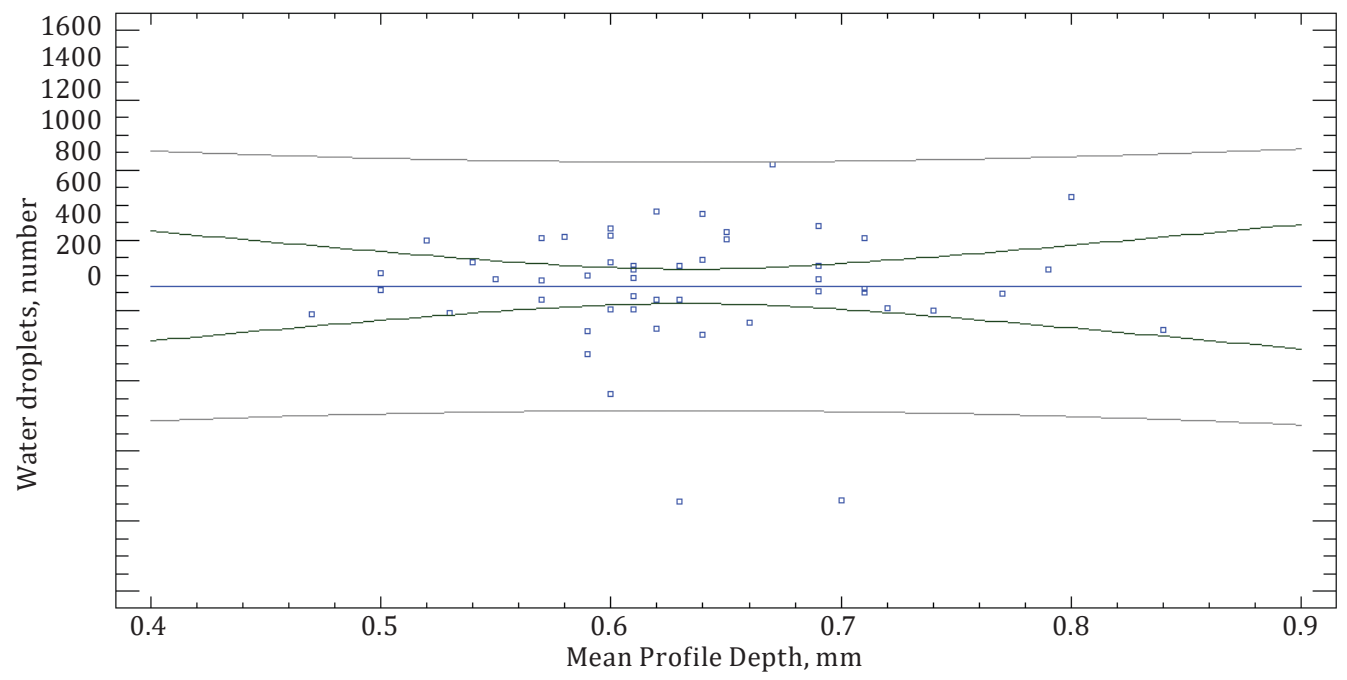

Figure 9. Number of water droplets on Test Track 2 
Plot of Fitted Model

Water droplets T3 $=972.176-456.894 \times$ MPD T3

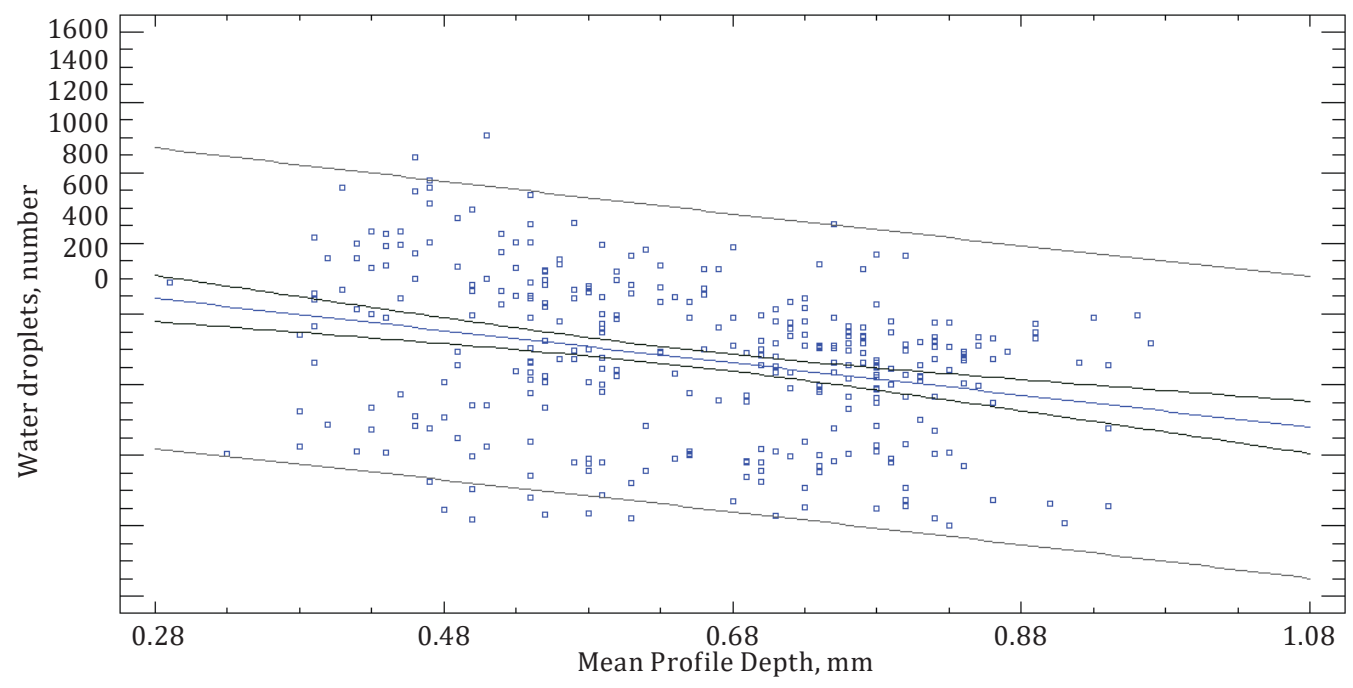

Figure 10. Number of water droplets on Test Track 3

Plot of Fitted Model

Water droplets T4 $=691.902-264.631 \times$ MPD T4

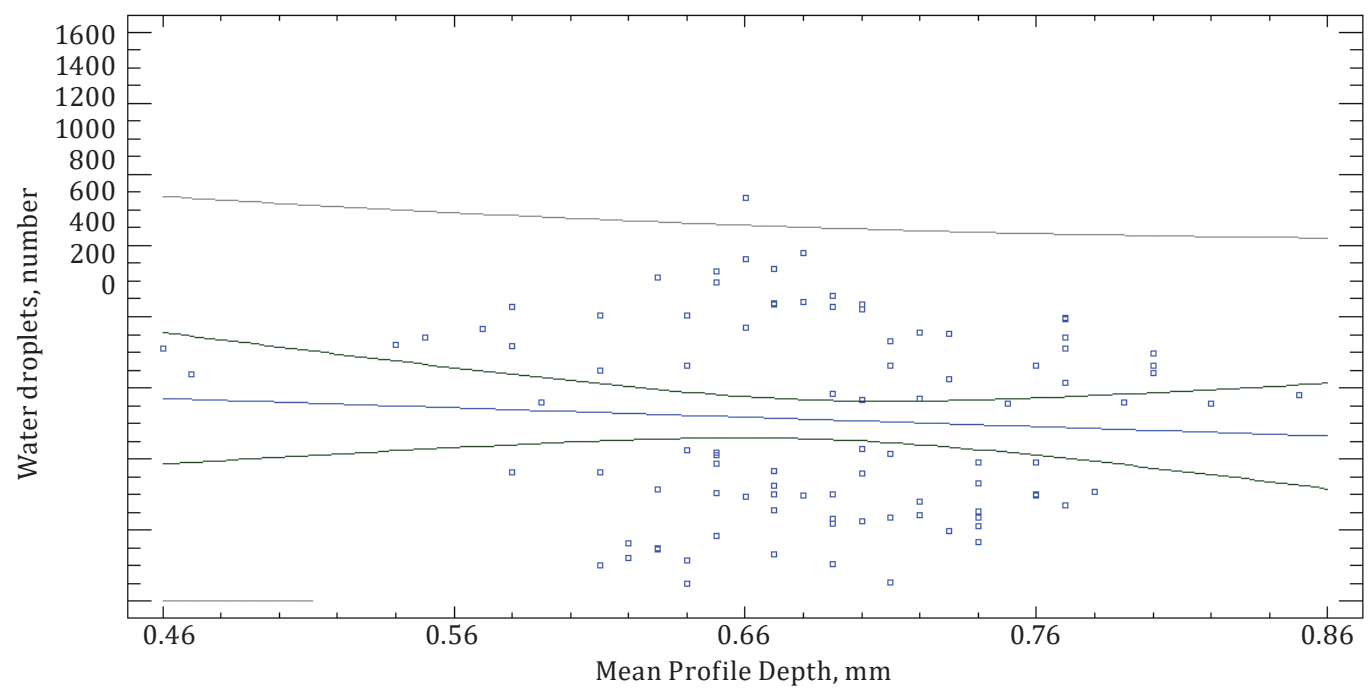

Figure 11. Number of water droplets on Test Track 4 
In light of the linear correlations, it should be noted that data Jose Antonio Ramos Garcia dispersion has an impact on the solidity of the relationship so, statistically, the relations between the pavement texture and a physical Influence of Texture on Drainability, Splash and Spray in Flexible phenomenon (splashed and sprayed water) appear weak, which can be Pavements seen in Table 2 .

Table 2. Correlation coefficient, $R^{2}$ and $p$-value for the linear regressions between MPD and splashed water (No. droplets)

\begin{tabular}{cccc}
\hline Test track & $\begin{array}{c}\text { Correlation } \\
\text { coefficient }\end{array}$ & $\boldsymbol{R}^{2}$ & p-value \\
\hline Test Track 1 & -0.045 & 0.002 & 0.540 \\
Test Track 2 & -0.002 & 0.000 & 0.988 \\
Test Track 3 & -0.181 & 0.033 & 0.002 \\
Test Track 4 & -0.062 & 0.004 & 0.551 \\
Test Track 5 & -0.248 & 0.062 & 0.003 \\
\hline
\end{tabular}

Plot of Fitted Model

Water droplets T5 $=897.114-488.198 \times$ MPD T5

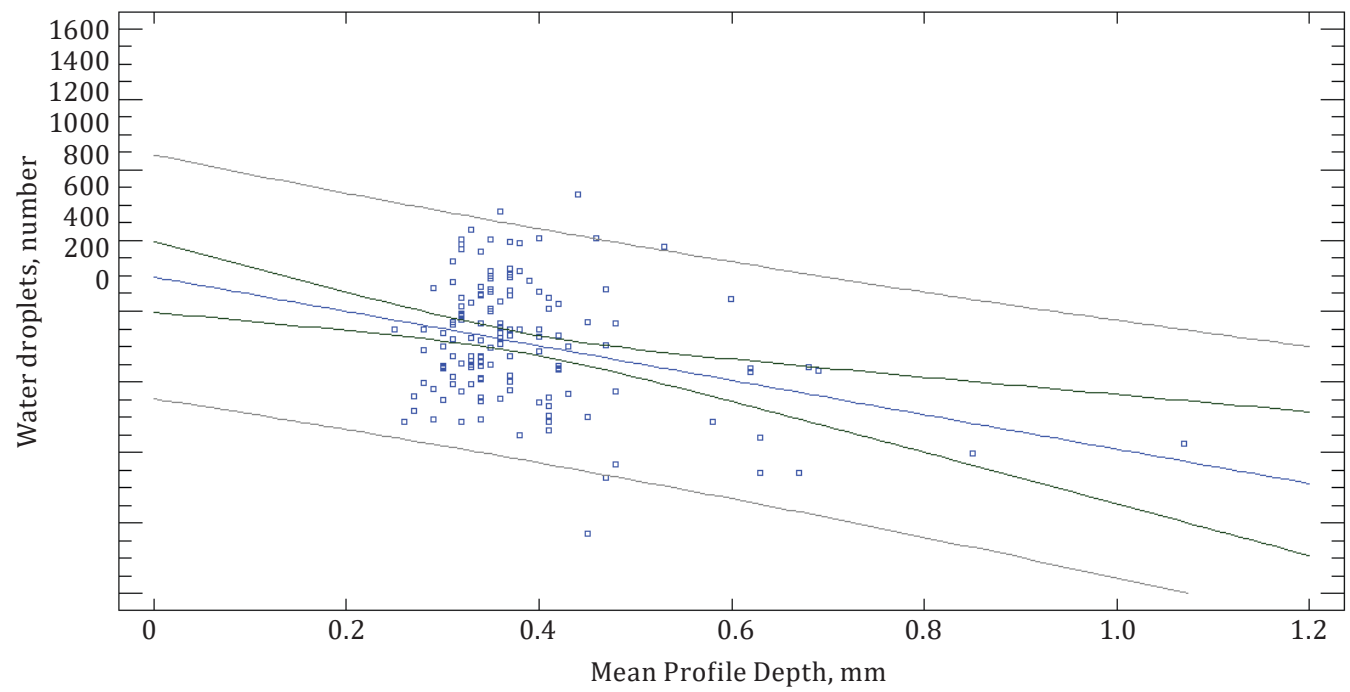

Figure 12. Number of water droplets on Test Track 5 
In order to get a more accurate perception of the relationship between the pavement texture and the physical phenomenon (splashed and sprayed water), a multiple variable analysis was carried out, involving in this case the mass of water droplets, which represents, physically, the water sprayed when a truck drives on a wet road. Considering the variables (pavement texture, which represents infrastructure influence; number of water droplets, which represents water sprayed; and mass of water droplets, meaning water splashed), scatterplot matrices were created and Pearson product-moment correlation and Spearman rank correlation were calculated. The scatterplot matrix is displayed in Fig. 13.

In this regard, Pearson product-moment correlations between each pair of variables were determined for each road test track. These correlation coefficients range between -1 and +1 , they measure the strength of the linear relationship between the variables. $p$-values below 0.05 indicate statistically significant non-zero correlations at the $95.0 \%$ confidence level. In several road test tracks, the results were moderately satisfactory taking into account the initial hypothesis. The number of water droplets shows a statistically significant relationship with the pavement texture, considering a value of -1 implies that all data points lie on a line for which $y$ decreases as $x$ increases, and the coefficient reached was -0.31 . The graphics from Fig. 14 to Fig. 18 show the Pearson product-moment correlations for Test Tracks 1 to 5 .

Regarding the Pearson product-moment correlations, only Test Track 5 provides a relevant Pearson value $(-0.31)$ between MPD texture and

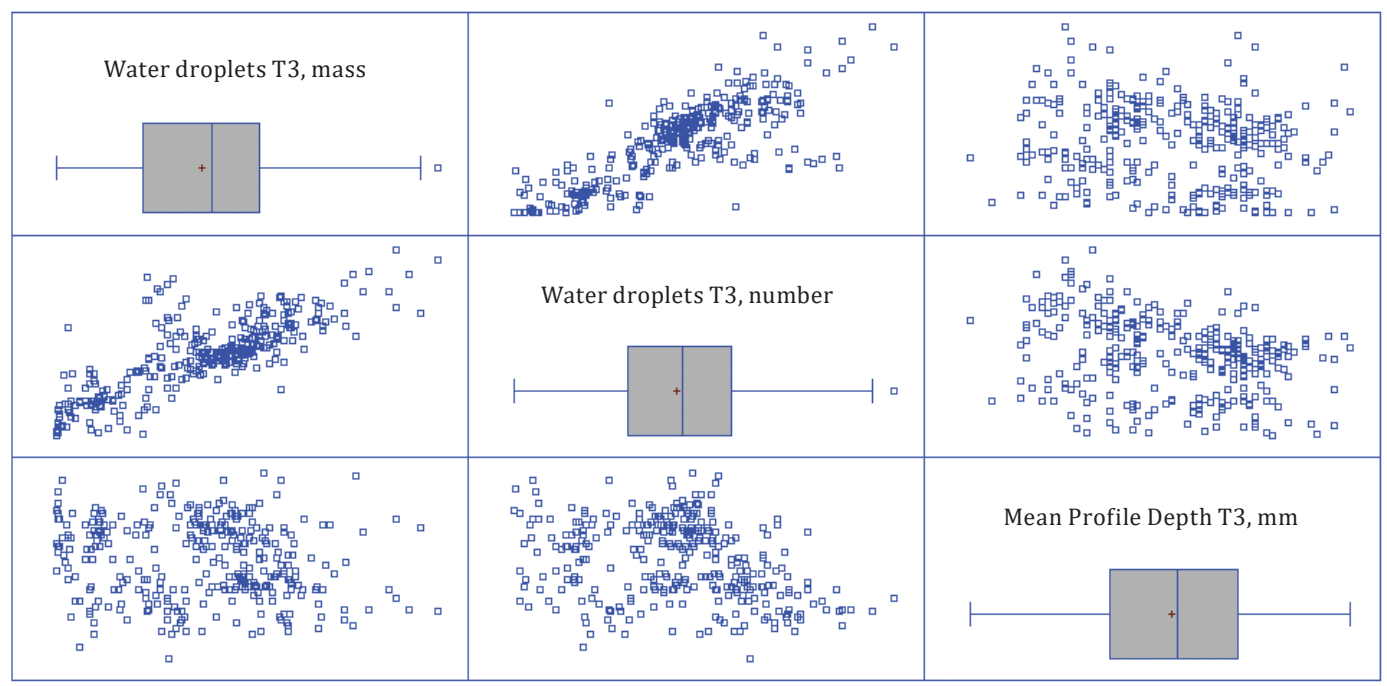

Figure 13. Scatterplot matrix of Road Section 3 
water splashed. Test Track 3 demonstrates a weak correlation value Jose Antonio Ramos $(-0.18)$, and the remaining test tracks do not show any apparent Pearson correlation.

\section{Garcia}

Influence of Texture on Drainability, Splash and Spray in Flexible Pavements

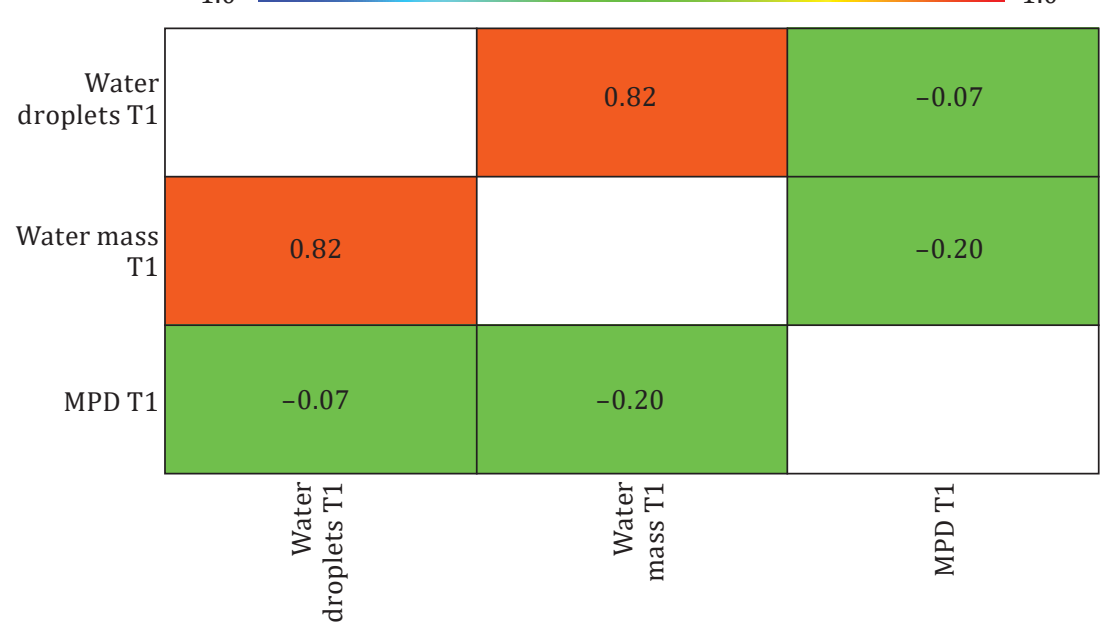

Figure 14. Pearson product-moment correlations between each pair of variables for Test Track 1

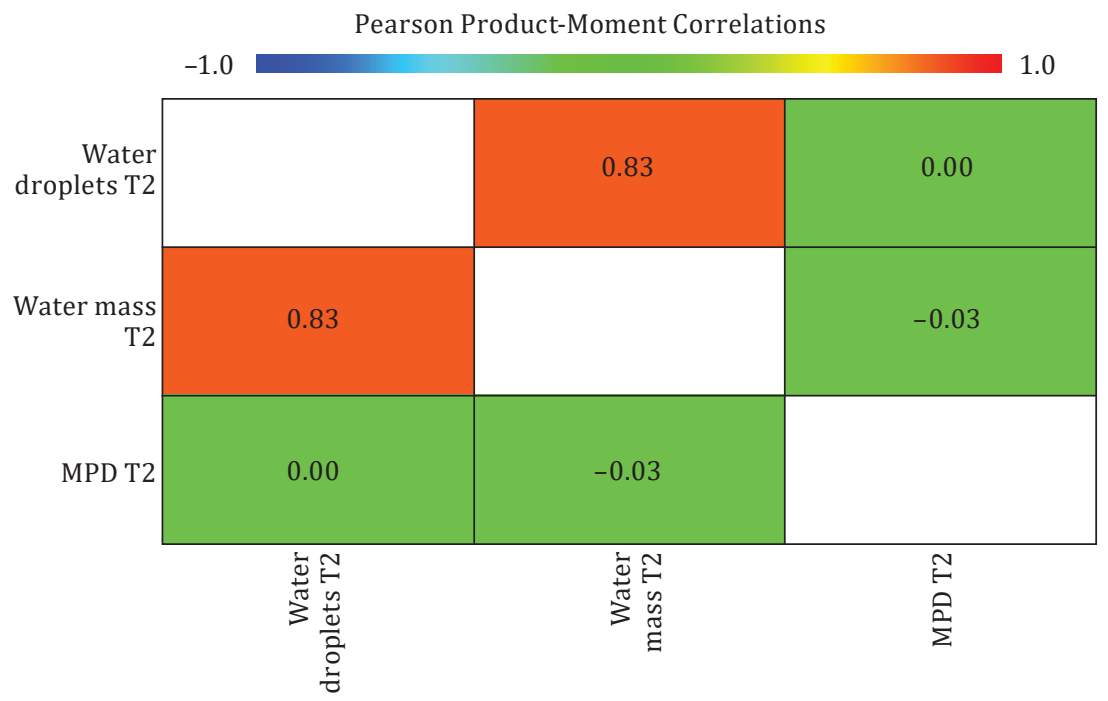

Figure 15. Pearson product-moment correlations between each pair of variables for Test Track 2 
THE BALTIC JOURNAL

OF ROAD AND BRIDGE ENGINEERING

2021/16(3)

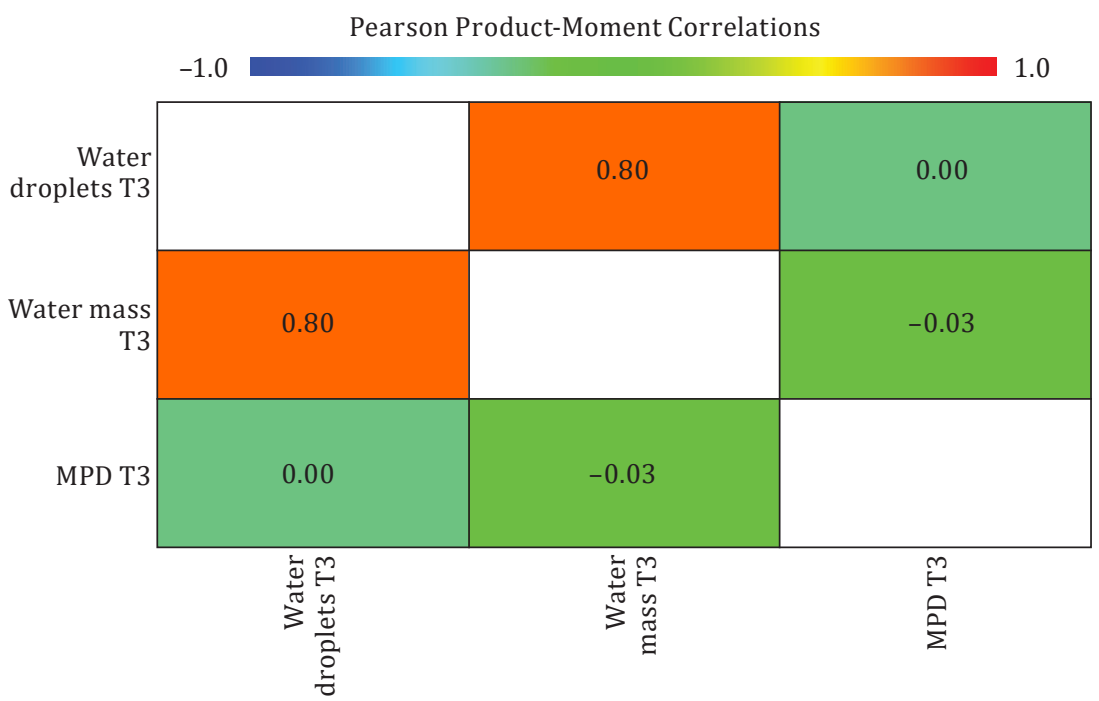

Figure 16. Pearson product-moment correlations between each pair of variables for Test Track 3

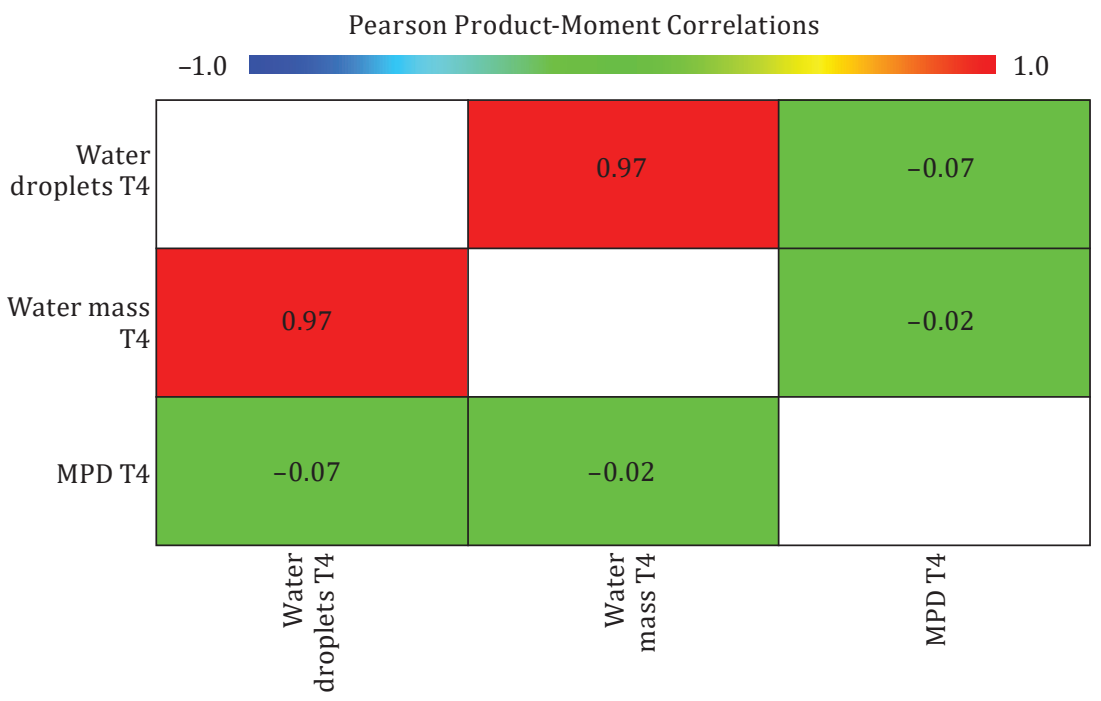

Figure 17. Pearson product-moment correlations between each pair of variables for Test Track 4 
Additionally, Spearman rank correlations between each pair of variables were calculated. These correlation coefficients range between -1 and +1 ; they measure the strength of association between the variables. In contrast to more common Pearson correlations, the Spearman coefficients are computed from the ranks of the data values rather than from the values themselves. Consequently, they are less sensitive to outliers than the Pearson coefficients. The results for road Test Track 3 can be seen in Table 3 .

Table 3. Spearman rank correlations for road Test Track 3

\begin{tabular}{c|ccc}
\hline & $\begin{array}{c}\text { Water droplets } \\
\text { [Mass] }\end{array}$ & $\begin{array}{c}\text { Water droplets } \\
\text { [Number] }\end{array}$ & $\begin{array}{c}\text { MPD } \\
\text { [mm] }\end{array}$ \\
\hline $\begin{array}{c}\text { Water droplets } \\
\text { [Mass] }\end{array}$ & & 0.8155 & -0.1133 \\
Water droplets & 0.8155 & 0.0000 & 0.0485 \\
[Number] & 0.0000 & & -0.1984 \\
MPD & -0.1133 & -0.1984 & 0.0006 \\
[mm] & 0.0485 & 0.0006 & \\
\hline
\end{tabular}

Pearson Product-Moment Correlations $-1.0$

Pearson Product-Moment Correlations

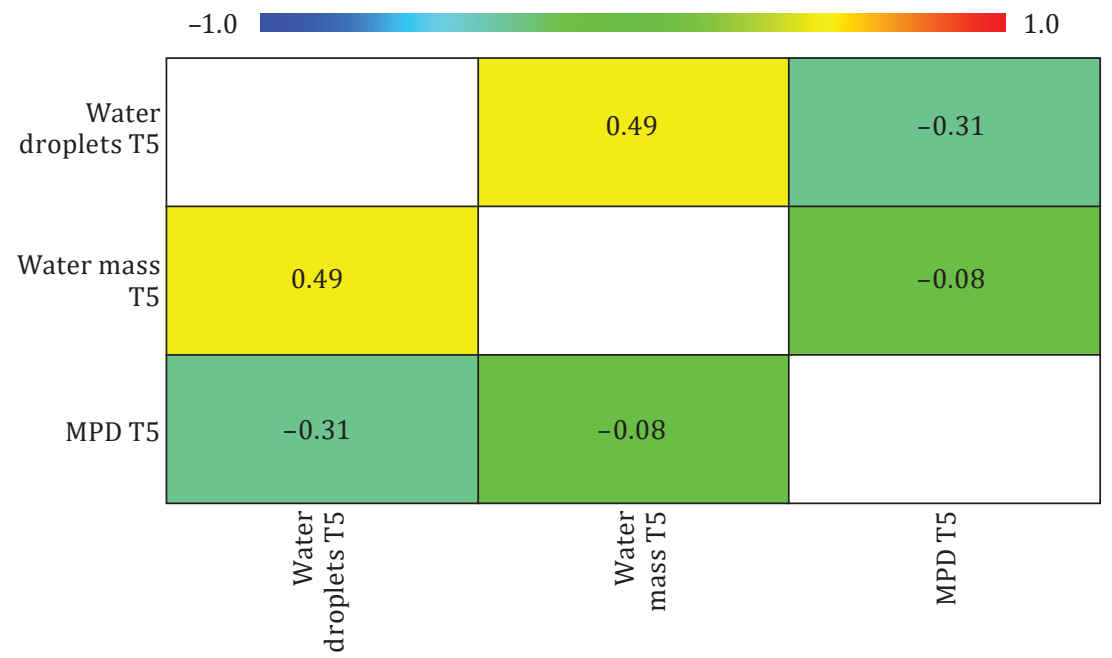

Figure 18. Pearson product-moment correlations between each pair of variables for Test Track 5
Jose Antonio Ramos

Garcia

Influence of Texture on Drainability, Splash and Spray in Flexible Pavements 
The upper number in each box is the Spearman coefficient, and the number in bold is the $p$-value correlation coefficient. $p$-values below 0.05 indicate statistically significant non-zero correlations at the $95.0 \%$ confidence level.

Considering the low $R$-squared correlation value, and with the aim of stating the statistical significance of water splashed depending to pavement texture for 5 test tracks, an ANOVA analysis was performed. In order to get proper and affordable results, MPD values were divided into five categories summarized in Table 4.

Table 4. MPD ranges for ANOVA analysis

\begin{tabular}{ccc}
\hline MPD range & Min & Max \\
\hline 1 & 0.00 & 0.30 \\
2 & 0.30 & 0.50 \\
3 & 0.50 & 0.70 \\
4 & 0.70 & 0.90 \\
5 & 0.90 & $\infty$ \\
\hline
\end{tabular}

The ANOVA analysis was performed by comparing water droplets as a dependent variable and MPD range from Table 4 as a factor. Statistical significance between the differences among MPD ranges for water droplets collected would confirm the hypothesis of this paper: the existence of a relationship between water splashed in a wet road and pavement texture. The performed analysis is displayed through three graphics: scatterplot by level code, graphical ANOVA and box-andwhisker plot, displayed from Fig. 19 to Fig. 21. 
Influence of Texture on Drainability, Splash and Spray in Flexible

Pavements

Scatterplot by Level Code

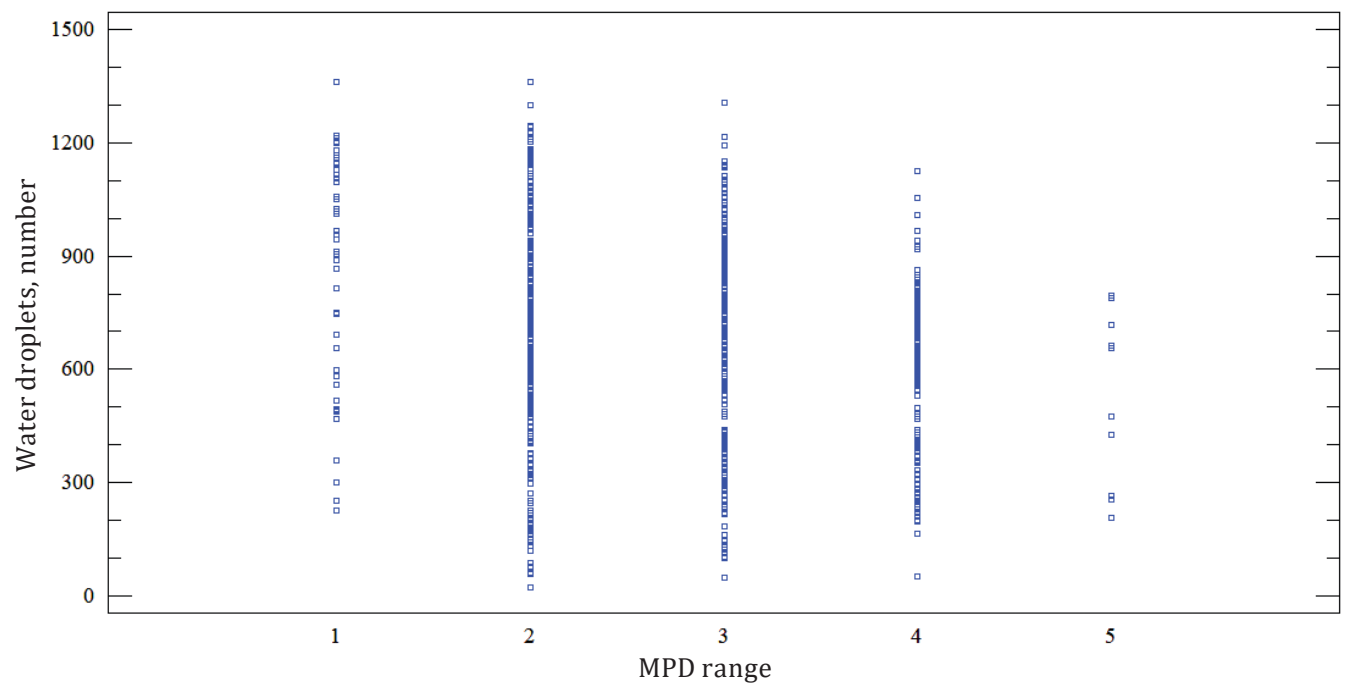

Figure 19. Scatterplot by level code. ANOVA analysis

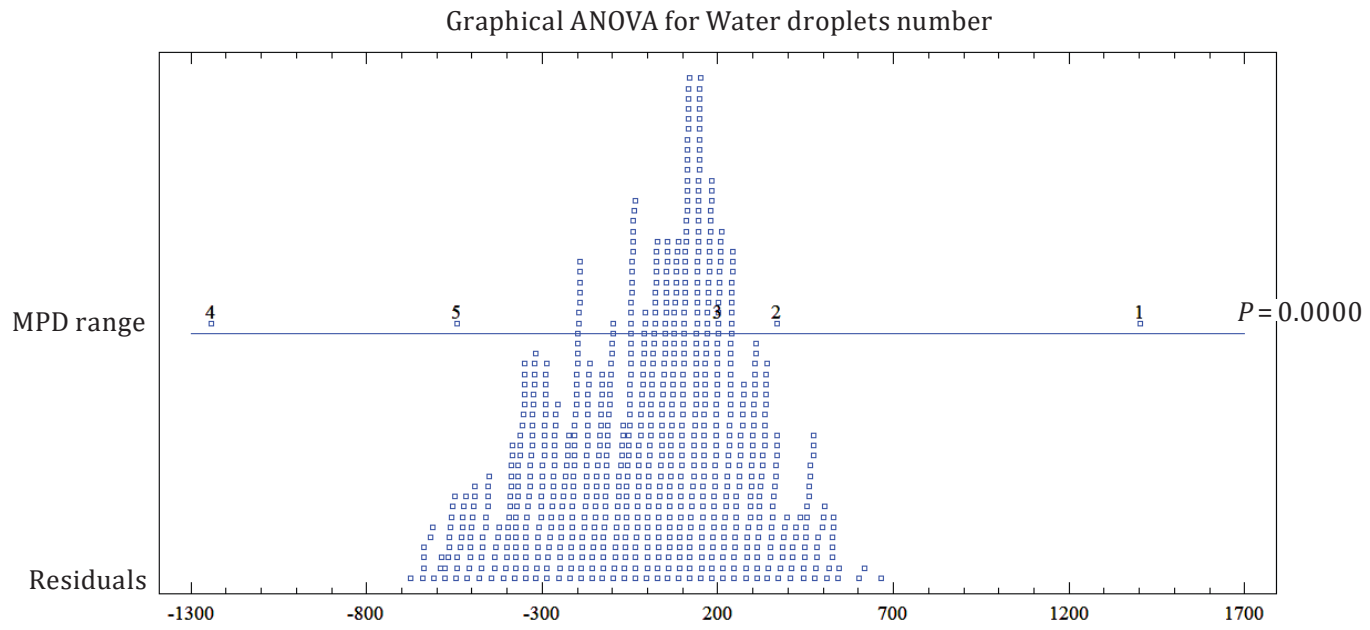

Figure 20. Graphical ANOVA plot for water droplets 


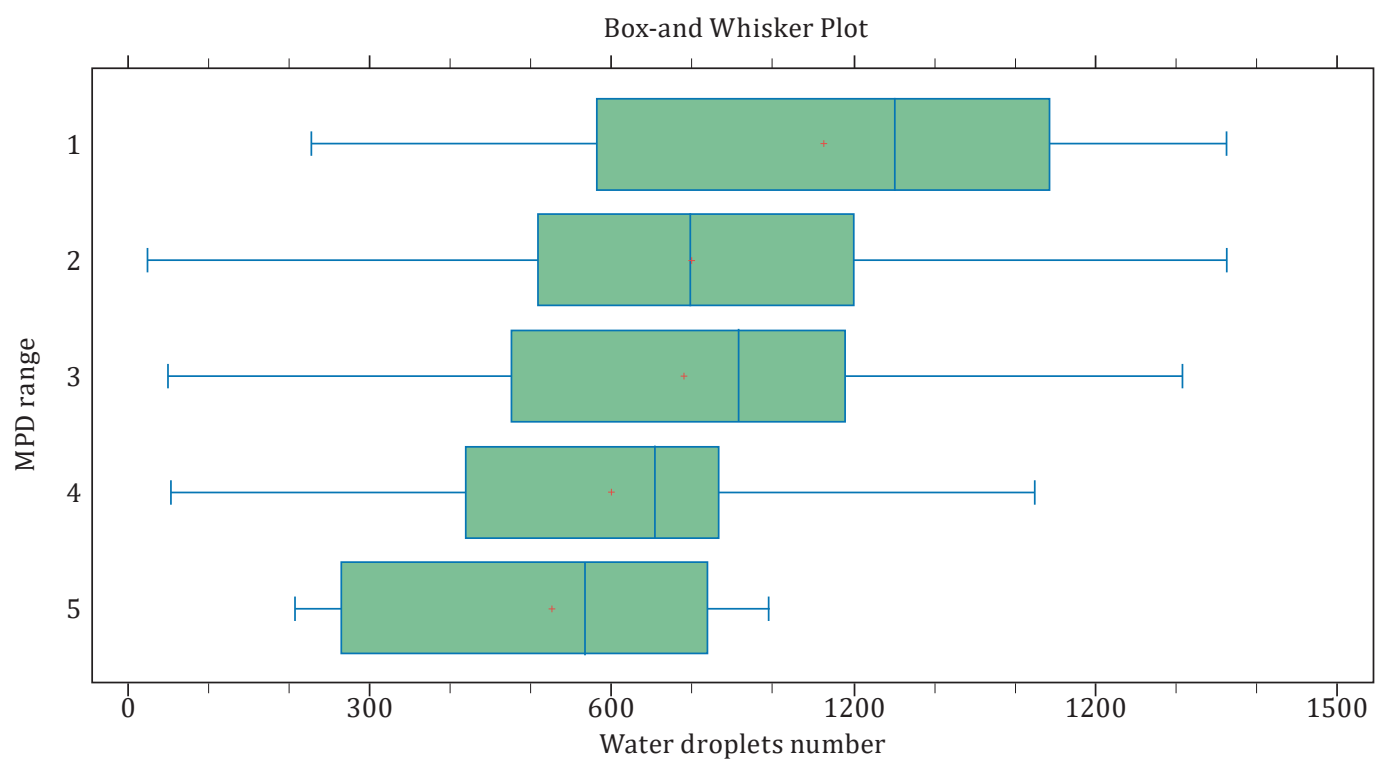

Figure 21. Box-and-whisker plot. ANOVA analysis

The results of the ANOVA analysis are given in Table 5.

Table 5. Results of ANOVA analysis of water droplets by MPD ranges

\begin{tabular}{cccccc}
\hline Source & Sum of Squares & $\boldsymbol{D f}$ & Mean Square & $\boldsymbol{F}$-ratio & $\boldsymbol{p}$-value \\
\hline Between groups & $3.18 \cdot 10^{6}$ & 4 & $7.95 \cdot 10^{5}$ & 11.39 & 0.0 \\
Within groups & $5.49 \cdot 10^{7}$ & 786 & 69816.9 & & \\
Total (Corr.) & $5.81 \cdot 10^{7}$ & 790 & & & \\
\hline
\end{tabular}

The ANOVA table decomposes the variance of water droplets number into two components: a between-group component and a within-group component. The $F$-ratio, which in this case equals 11.3911, is a ratio of the between-group estimate to the within-group estimate. Since the $p$-value of the $F$-test is less than 0.05 , there is a statistically significant difference between the mean water droplets number from one level of MPD range to another at the 5\% significance level. This result confirms that the range of pavement macrotexture (infrastructure factor) has an influence on the water splashed from a tire rolling over wet road. 
Finally, in order to get a better view after the qualitative analysis Jose Antonio Ramos f the survey data, a quantitative analysis was performed; it is shown below. As mentioned earlier in the section "Methodology", the MPD values were collected simultaneously with the drainability test, and the longitudinal results for this parameter are shown in the chart below. Potentially, observations could have been made using the results displayed separately. However, an entire chart was deemed to be preferable in order to have a longitudinal view of the survey data, particularly of the differences between pavement sections with different surface conditions. The quantitative analysis is displayed in Fig. 22.

The test tracks have different texture ranges. However, in a continuous display, the trend in the relationship is more noticeable. When pavement texture (light blue) increases, the amount of water splashed declines in the majority of test tracks. A reasonable explanation for this behaviour would lie in the physical concept of texture depth: when rainfall has more space to be deposited, more water remains in the pavement texture between aggregates. The natural consequences are a reduction of the water film thickness in open-graded pavements and a decrease of splashed water with traffic flow. A sample water distribution across the pavement texture is shown in Fig. 23.

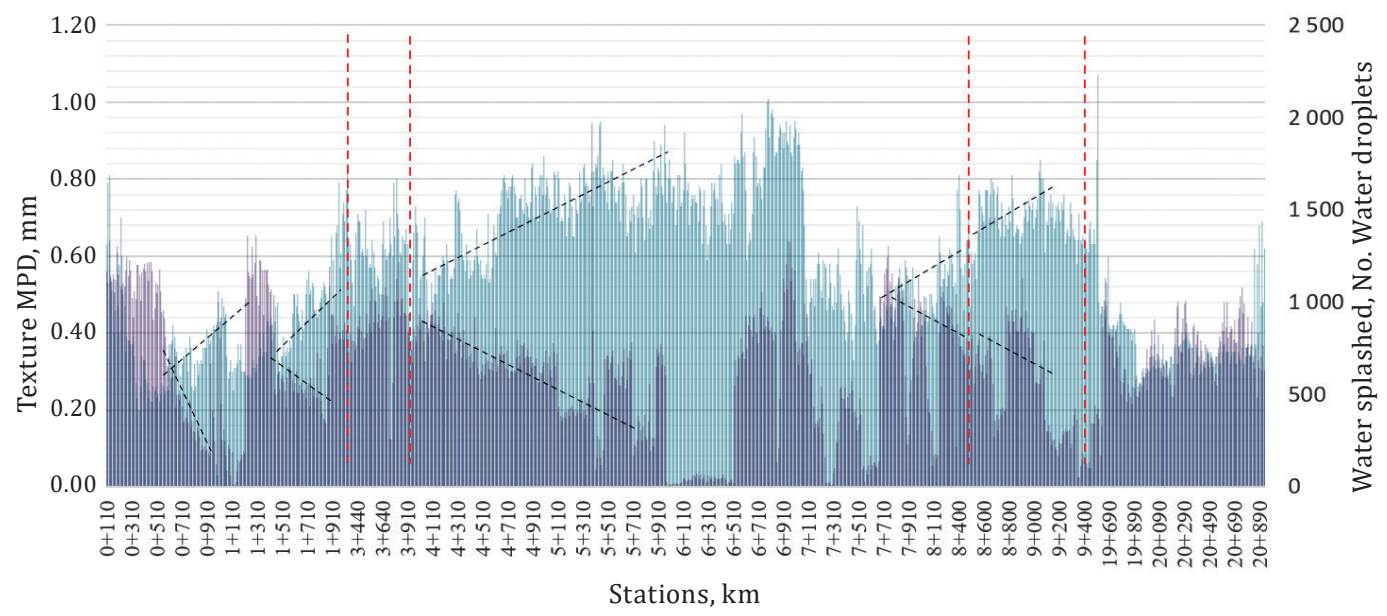

=Texture MPD, mm $\quad$ Water splashed, No. Water droplets

Figure 22. Longitudinal representation between pavement MPD and water droplets through the road stations 


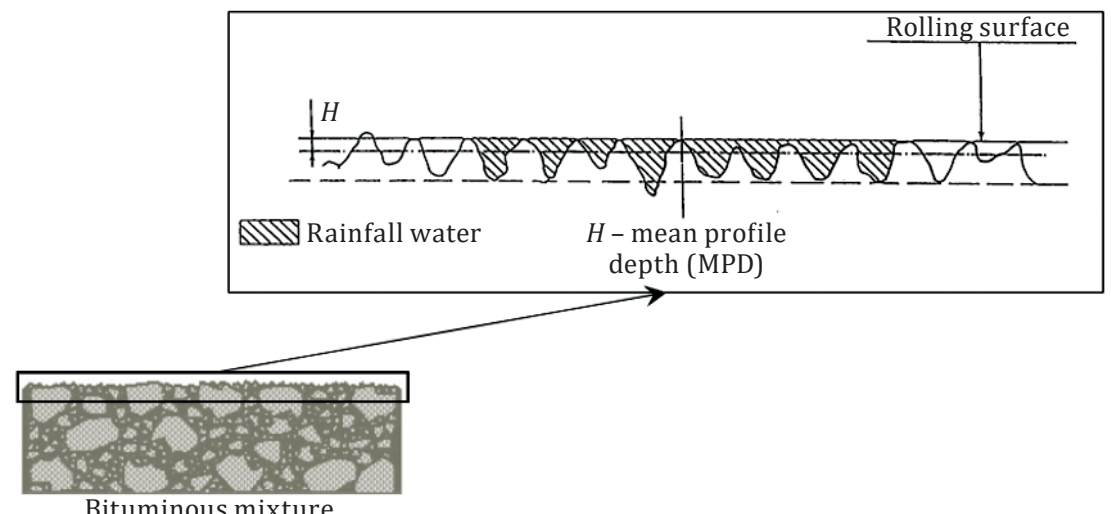

Bituminous mixture

Figure 23. Rainfall water in the pavement texture

\section{Conclusions}

In light of the results obtained in this study, having conducted the ANOVA analysis, it has been confirmed that the range of pavement macrotexture (infrastructure factor) has certain influence on the water splashed from a tire rolling over the wet road. In addition, there seems to be a significant relationship between the pavement texture and water splashed in Test Tracks 3 and 5, which apparently varies inversely. However, this conclusion cannot be generalized for other test tracks.

In order to get more conclusive results, the authors consider increasing the sample size (from 5 tracks to 15-20 tracks) in future research. Analysis of other infrastructure variables could be helpful in setting the boundary conditions of the relationship between water splashed and the infrastructure. Although the experiment was carried out on the relatively horizontal roads (low longitudinal slope), the influence of road alignment (i.e., longitudinal and cross slope) on the water splashed appears to be another interesting field of research. A future research shall involve more tests with other tracks in order to find an empirical correlation between the road texture and splashed water. In this regard, more studies are necessary in the future to make general and broader conclusions.

It was possible to make the findings presented in this study thanks to the use of the "Traffic Speed Drain Meter", which allows the tests to be reproduced on other roads in different countries or regarding different bituminous mixtures and road conditions. The equipment could make drainability assessment easier and repeatable (dynamic vehicle) at 
an affordable cost (high performance of data collection). The range of pavement types analysed may be considered another contribution, since previous studies covered the surveys using only two types of pavements: open-graded and dense-graded mixtures. This study has aimed to get a bigger sample of pavement surfaces with different aggregate grading, covering different MPD ranges.

Many studies have been carried out to reduce splash and spray considering such factors as car tires, protective devices, and traffic speed. In this regard and according to the obtained results, pavement texture appears to be another significant factor that should be considered when adopting the infrastructure approach. Consideration of the consequences the surface design has on splash and spray production can help pavement engineers design a better surface finish. It may also assist road maintainers to reduce splash and spray problems and the related inconveniences in conditions of wet weather, providing opportunity to ensure that the roads under their responsibility have the proper texture.

The experimental method met suitable features to minimize the contamination of results (relatively flat terrain avoiding distortion in water collection because of longitudinal slope, roads with transverse slope of $2 \%$, temperate climate, etc.). Nevertheless, the sample expansion is considered the main way to improve the accuracy of the correlation studies between the pavement texture and water splashed. To achieve more quantitative conclusions (i.e., the development of a relationship equation, the variation of the relationship for different climates, etc.), it is necessary to obtain a wider sample of roads surveyed in different continents. The experiment presented here is a starting point; this line of research will be followed in future.

\section{Acknowledgements}

The authors want to acknowledge the contribution of Fernando Sanchez Dominguez made in his prior work on the definition of drainability indicators and his important role in ensuring survey equipment performance.

\section{REFERENCES}

Anderson, D. A., Huebner, R. S., Reed, J. R., Warner, J. C., \& Henry, J. J. (1998). Improved Surface Drainage of Pavements. Final Report, PTI 9825.

http://onlinepubs.trb.org/Onlinepubs/nchrp/nchrp_w16.pdf 
Ashton, M., \& Baas, P. (1998). Spray and Wind Buffeting from Heavy Vehicles: A Literature Review.

Benatov, L. B., Pérez, F. E., \& Miró, R. (2013). Sistema para la evaluación dinámica de la drenabilidad de pavimentos de carreteras mediante técnicas de visión artificial. Oficina Española de Patentes y Marcas.

Briessinck, M., \& Moffatt, M. (2017). State of the Art in Monitoring Road Condition. In Global Approaches on Sustainable Pavements. Permanent International Association of Road Congresses (PIARC).

Brochard, J., \& Khoudeir, M. (2010). Device for Evaluation the State of Wetting of a Surface. United States Patent Office.

Campbell, J. D. (1984). Instrumentation for Measuring the Effectiveness of Truck Spray Supression Devices. Report No. UMTRI-84-27.

Chatfield, A. G., Reynolds, A. K., \& Foot, D. J. (1979). Waterspray from Heavy Goods Vehicles: An Assessment of Some Vehicle Modifications. No. VSE513. https://trid.trb.org/view/148820

Eklund, L. E. (1991). Spray-Suppressant Splash Guard for Vehicles. United States Patent Office.

Escriba, S., \& Jiménez, N. (2015). Medidor continuo de drenabilidad y permeabilidad in situ para pavimentos de carretera. Oficina Española de Patentes y Marcas.

Flintsch, G. W. et al. (2014). Splash and Spray Assessment Tool Development Program.

Flintsch, G. W., Williams, B., Gibbons, R., \& Viner, H. (2012). Assessment of the Impact of Splash and Spray on Road Users. Results of Controlled Experiment. Transportation Research Record: Journal of the Transportation Research Board, 2306(1), 151-160. https://doi.org/10.3141/2306-18

Koppa, R. J. et al. (1985). Heavy Truck Splash and Spray Testing: Phase II.

Koppa, R. J. et al. (1992). Aging Driver Needs for Mobility in an Automobile Oriented Region: 5 Research Studies. Report No. SWUTC/92/71242-2.

Marion, N. (1915). Mudguard for Automobiles and the Like. United States Patent Office.

Maycock, G. (1966). The Problem of Water Thrown up by Vehicles on Wet Roads. RRL Report No. 4.

Moffatt, M. (2016). SOTA Report on Road Condition Monitoring and Road/Vehicle Interaction. Proposals.

Mogrovejo, D. E., Flintsch, G. W., Katicha, S. W., de León Izeppi, E. D., \& McGhee, K. K. (2016). Enhancing Pavement Surface Macrotexture Characterization by Using the Effective Area for Water Evacuation. Transportation Research Record: Journal of the Transportation Research Board, 2591(1), 80-93. https://doi.org/10.3141/2591-10

National Highway Traffic Safety Administration. (1994). Splash and Spray Suppression: Technological Developments in the Design and Testing of Spray Reduction Devices for Heavy Trucks. Report to Congress DOT HS 808085.

Pérez-Jiménez, F., Martínez, A., Sánchez-Domínguez, F., \& Ramos-García, J. A. (2011). System for Measuring Splash on Wet Pavements. Transportation Research Record: Journal of the Transportation Research Board, 2227(1), 171-179. https://doi.org/10.3141/2227-19 
Pike, A. M., Hawkins, H. G. J., \& Carlson, P. J. (2007). Evaluating the Retroreflectivity of Pavement Markings Materials under Continuous Wetting Conditions, Transportation Research Record: Journal of the Transportation Research Board, 2015(1), 81-90. https://doi.org/10.3141/2015-10

Pilkington, G. B. I. (1990). Splash and Spray. In W. Meyer \& J. Reichert (Eds.), Surface Characteristics of Roadways (pp. 528-541). ASTM. https://doi.org/10.1520/STP23387S

Plocher, D. A. (2011). Experimental Investigation of Spray Development Inmediately Behind a Tire Rolling on a Wet Surface (PhD Thesis, University of Southern California).

Resendez, Y. A., Sandberg, U., Rasmussen, R. O., \& Garber, S.(2007). Characterizing the Splash and Spray Potential of Pavements. US Department of Transportation, Federal Highway Administration, 11(6).

Ritter, T. E. (1974). Truck Splash and Spray Tests at Madras, Oregon. Report No. AR-955.

Rungruangvirojn, P., \& Kanitpong, K. (2010a). Measurement of Visibility Loss Due to Splash and Spray: Porous, SMA and Conventional Asphalt Pavements. International Journal of Pavement Engineering, 11(6), 499-510. https://doi.org/10.1080/10298430903578945

Rungruangvirojn, P., \& Kanitpong, K. (2010b). Measurement of Visibility Loss Due to Splash and Spray: The Comparison between Porous Asphalt, SMA and Conventional Asphalt Pavements. In TRB 2009 88th Annual Meeting (pp. 499-510). Transportation Research Board.

Sánchez Domínguez, F., Ramos García, J. A., \& Álvarez Loranca, R. L. (2012). Systems and Tools for the Evaluation of Road Quality Indicators. In European Pavement and Asset Management Conference (EPAM). Sweden, Mälmo.

Sheppard, P. (1989). Review of Heavy Vehicle Spray Alleviation.

Society of Automobile Engineers. (2011). Recommended Practice for Splash and Spray Evaluation. No. J2245.

https://www.sae.org/standards/content/j2245_201105/

Srirangam, S. K., Anupam, K., Scarpas, A., Kasbergen, C., \& Kane, M. (2014) Safety Aspects on Wet Asphalt Pavement Surfaces through Field and Numerical Modeling Investigations. Transportation Research Record: Journal of the Transportation Research Board, 2446(1), 37-51. https://doi.org/10.3141/2446-05

Takashi, C., Okihiko, H., \& Yukio, I. (1994). Method and Apparatus for Testing Water Permeability Performance on Road Pavement. Japan Patent Office.

Tang, L., \& Flintsch, G. W. (2015). Assessment of Splash and Spray Potential of Experimental Quiet Pavement Surfaces. Report No. VT 2012-01.

Tennent, T. (1886). Velocipede Skate. United States Patent Office.

Tromp, J. P. M. (1985). Splash and Spray by Lorries. Report No. R-85-5.

UNE 41201:2020 IN. Road and airfield surface characteristics. Procedure for measuring the sideway force coefficient (SFC) with SCRIM. Asociación Española de Normalización. https://www.une.org/encuentra-tu-norma/ busca-tu-norma/norma/?Tipo=N\&c=N0064889

Weir, D. H., Ringland, R. F., Heffley, R. K., \& Ashkenas, I. L. (1971). An Experimental and Analytical Investigation of the Effect of Truck-Induced 
THE BALTIC JOURNAL OF ROAD AND BRIDGE ENGINEERING $2021 / 16(3)$

Aerodynamic Disturbances on Passenger Car Control and Performance. Report No. FHWA-RD-71-3.

Weir, D. H., Strange, J. F., \& Heffley, R. K. (1978). Reduction of Adverse Aerodynamic Effects of Large Trucks Volume I. Report No. FHWA-RD-79-84. Federal Highway Administration.

Yu, B., \& Sun, Y. (2018). Simulation of Impact of Water-Film Spray on Visibility. Journal of Transportation Engineering Part B: Pavements, 144(4), 1-7. https://doi.org/10.1061/jpeodx.0000085 